\title{
GUIMARÃES ROSA E UM RIO ALÉM DAS MARGENS
}

Simone de Souza Braga Guerreiro

Instituto Superior de Ciências Humanas e Sociais Anísio Teixeira - ISAT. Doutora.

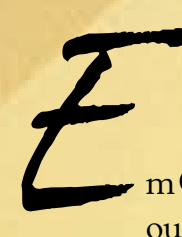

m Guimarães Rosa, muitomais doquequestõeslinguísticas ou regionalistas, o que se destaca é a experiência humana que, de certa forma, torna-se transcendente, pois é através de seu entendimento do que é a existência em si que ele consegue captar uma terceira margem do ser. A inserção de uma terceira margem ao rio reflete uma espécie de inquietação, pois Guimarães Rosa nos sugere abandonar margens preestabelecidas e, talvez, seguras, e estabelecer outra. O presente trabalho analisa o conto "A terceira margem do rio" procurando marcar os caminhos em que se busca pelo transcendente, por um percurso que possa romper os limites entre o mundo cotidiano e o mundo metafísico. Ao instaurar-se a terceira margem, instaura-se certa descontinuidade necessária que leva o ser a perceber-se como autêntico e, aí sim, livre.

Palavras-chave: Filosofia. Memória. Verdade.

Publicado em 1962, no livro Primeiras estórias, "A terceira margem do rio" é um conto que permite uma infinidade de leituras. Nesse conto de Guimarães Rosa, muito além das experimentações linguísticas e dos elementos regionalistas, o que se destaca é uma experiência humana que se torna transcendente. É na "terceira margem" que encontramos inseridos o homem e o mundo. No complexo universo do autor, podemos observar a multiplicidade de caminhos que permeiam sua ficção. E é esta postura que nos permite trafegar por veredas filosóficas. Como aponta Antonio Candido, percebemos que Guimarães Rosa elabora "um universo autônomo, composto de realidades expressionais e humanas que se articulam em relações originais e harmoniosas, superando por milagre o poderoso lastro de realidade tenazmente observada, que é a sua plataforma" (CANDIDO, 2006, p. 112). 
É sobre esse aspecto que o homem, vivendo em uma canoa no centro de um rio, na recriação rosiana, torna-se um homem peculiar, pois ele é aquele que será composto de elementos deformados a partir de elementos reais. E assim, o rio e suas margens são o local que permite alcançar uma realidade mais ampla e significativa. A imagem do rio, de suas margens e da travessia é vista aqui como um espaço de questionamento da condição humana. É nesse sentido que a narrativa é uma busca pela transcendência, pelo desejo de interferir nos condicionamentos limitadores do cotidiano para instaurar novos sentidos.

Na história de Guimarães Rosa, há um momento em que o filho mais velho narra um fato significativo sobre seu pai:

Nosso pai não voltou. Ele não tinha ido a nenhuma
parte. Só executava a invenção de se permanecer
naqueles espaços do rio, de meio a meio, sempre
dentro da canoa, para dela não saltar, nunca mais. A
estranheza dessa verdade deu para estarrecer de todo a
gente (ROSA, 1968, p. 33).

O movimento gerador de "A terceira margem do rio" é o gesto do pai. A tensão dramática do texto é dada por esse gesto. O pai e a sua escolha nos colocam para além das duas margens do rio. Essas duas margens denotam duas realidades que se desenvolvem no conto: da superfície e das profundezas.

Na realidade da superfície está um pai que tem uma família, uma fazenda e que é amigo dos vizinhos e do povo do pacato vilarejo. Um homem integrado à realidade corrente de um determinado lugar no sertão. Um homem "cumpridor, ordeiro, positivo" (ROSA, 1968,p. 32).

Subitamente, e sem nenhuma explicação, ele resolve abandonar a todos para viver sozinho numa canoa. O pai se afasta sem ir a nenhum lugar, ou melhor, ele vai a um não-lugar. Não há nada de anormal acontecendo que o leve a essa atitude - as hipóteses de loucura, doença ou promessa são prontamente descartadas ele providencia a construção de uma canoa, um gesto cumprido quase friamente, sem fornecer explicações e sem dúvidas. Uma canoa que foi feita especialmente para ele:

Encomendou a canoa especial, de pau de vinhático, pequena, mal com a tabuinha da popa, como para caber justo o remador. Mas teve que ser toda fabricada, escolhida forte e arqueada em rijo, própria para dever durar na água por uns vinte ou trinta anos (ROSA, 1968, p. 32). 
Uma vez pronta a canoa, ele se despede da família e embarca na solidão do largo rio, onde passa a viver uma longa jornada de dias e noites, meses e anos a fio sem jamais retornar à terra.

A superfície é onde o rio toca a canoa, é o mundo que se vê. O mundo racional representado pelas duas margens. A verdade do pai não se encontra nessas margens. As duas margens do rio se apresentam como um universo racionalista e lógico numa síntese totalizadora da vida. Enquanto a família, os amigos e os vizinhos estão presos a uma das margens do rio, ele se afasta de tudo isso e avança para o interior do rio em busca de uma terceira margem. O pai numa canoa torna-se fluido, quase incorpóreo, que desaparece e aparece, transforma-se fisicamente, mas é ele mesmo. Perto e distante. O gesto do pai apresenta-se como misterioso e estranho, pois a razão não consegue elucidar.

Na narrativa tecida por Guimarães Rosa, há o mínimo de informações, pois se prende a um só conflito, a uma única ação. Não há nomes próprios (pai, filhos, mãe, amigos), nem mesmo o rio tem nome, não há espaço para a individualidade. Na realidade criada pelo autor, não há excentricidade no gesto do pai, há um homem que vai ao encontro de suas profundezas, de seu eu interior. É um homem que deseja estar diante de si mesmo, um homem que tem olhos apenas para o que é verdadeiramente essencial. Que se entrega a esse objetivo e nele permanece. E esse gesto não pode ser compreendido pelo senso comum. Ao entrar nas águas do rio, o pai alcança outra esfera. Na canoa está um homem que extrapola a lógica racionalista, utilitária, e se entrega à essência do homem, assumindo a verdade do ser.

Um rio tem duas margens, mas no conto são três: duas concretas, terrenas, conhecidas e uma abstrata, desconhecida. A decisão do pai simboliza o seu desejo de realizar algo que é necessário, sem interferências. Entrando em acordo com a sua essência, ele se interioriza para conhecer as profundezas de sua alma. Ele escolhe não mais viver na superfície (mundo das aparências) e torna-se sujeito ativo do próprio destino. Essa decisão tão radical equivale a uma libertação. A uma liberdade que consiste em dispor de si mesmo, libertando-se do exterior para seguir o rumo da própria natureza. A liberdade é um ser em sua totalidade, na medida em que ele renega a rotina cotidiana e instaura sua própria rotina fundada metaforicamente nas águas que o levam, torna-se um espírito livre, na vivência do espaço solidificada nas águas que o levam. $\mathrm{Na}$ alegoria do rio, o pai vivencia o exercício de sua subjetividade, livre, desprendido 
dos elementos sociais e familiares, despojado da matéria, no pleno diálogo com a natureza. Como numa experiência onírica, o pai inicia uma nova forma de vida. Ao deixar a terra, renasce, batiza-se e reinaugura-se, não mais como homem de ação, mas como homem de contemplação. Despojado de tudo que representa o mundo material, investe na profundeza do ser no mundo e na liberdade que se encontra não no "eu" superficial, mas no "eu" profundo. A essência da verdade é a liberdade, pois a sua escolha é uma verdade que não se pode realizar a não ser através da liberdade de quem age. A sua liberdade existe na mesma proporção em que se manifesta o eu profundo e viceversa. O personagem se alegoriza na aventura do homem que tende a dominar as forças primitivas para alcançar a harmonia interior.

A inserção de uma terceira margem ao rio reflete uma espécie de inquietação (o filho representa essa inquietação), pois a fabulação rosiana nos sugere abandonar margens preestabelecidas e, talvez, seguras, e estabelecer uma outra. Essa narrativa fala de uma busca pelo transcendente, por um caminho que possa romper os limites entre o mundo cotidiano e o mundo metafísico. Ao instaurar a terceira margem, instaurase certa descontinuidade necessária que leva o ser a perceberse como um ser autêntico, esse é o ideal percebido por sua consciência.

Então vemos que o pai se afasta da realidade da superfície. E tem uma nova realidade fundamentada numa existência enraizada na verdade como liberdade. Esse laço entre a verdade e a liberdade não é fácil de ser aceito, não é fácil de ser seguido. Nessa interpretação, a liberdade é conquistada a partir da transcendência que acompanha o ser humano como tal.

A atitude do pai afetou e transformou definitivamente a vida de toda a família. Mas, apesar disso, todos conseguiram seguir o seu rumo cotidiano. Menos o filho mais velho, que parecia aprisionado à atitude inexplicável do pai:

Minha irmã se mudou, com o marido, para longe daqui. Meu irmão resolveu e se foi, para uma cidade. Os tempos mudavam, no devagar depressa dos tempos. Nossa mãe terminou indo também, de uma vez, residir com minha irmã, ela estava envelhecida. Eu fiquei aqui, de resto. Eu nunca podia querer me casar. Eu permaneci, com as bagagens da vida. Nosso pai carecia de mim, eu sei - na vagação, no rio no ermo - sem dar razão do seu feito (ROSA, 1968, p. 35). 
Certo dia, porém, quando o filho já trazia os primeiros fios de cabelos brancos, sua angústia com o destino do pai se intensifica. Assim, ele vai até a margem do rio e acena com um lenço branco para o pai que, de repente, surge e diz:

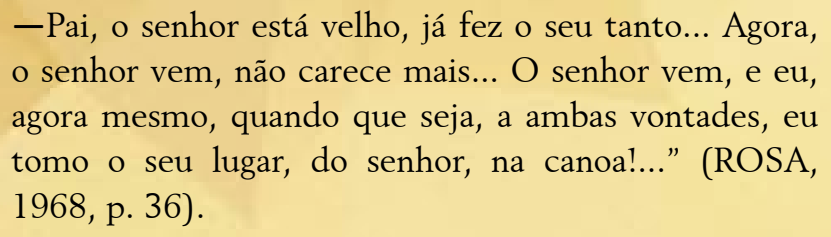
o senhor vem, não carece mais... O senhor vem, e eu, agora mesmo, quando que seja, a ambas vontades, eu tomo o seu lugar, do senhor, na canoa!..." (ROSA, 1968, p. 36).

O pai escutou, ficou em pé na canoa e num gesto de concordância remou em direção ao filho como se alegrasse com a oferta. Apavorado com a aproximação do pai e com o que isso significava, ele foge.

O filho não possui a força existencial para não se deixar dominar pelo mundo da aparência (superfície) e, assim, dar continuidade ao projeto de seu pai. Conceber o ato do pai como um absurdo resultante de uma escolha individual é um erro que levará a outro erro: a proposta de substituição do filho. Essa possibilidade o amedrontou. O medo intenso que o filho sentiu o fez renegar o pai. Parece que uma porta de acesso ao mundo transcendente fechou-se. Contudo ainda há uma possibilidade, o filho vislumbra uma solução extrema e absoluta em seu desejo de que, após a morte, o depositem numa canoa pequena, e assim percorrer o rio abaixo e o rio acima, como fez seu pai.

Em face dos atos e sentimentos vividos, o grande problema para o filho, na sua condição de homem, seria encontrar a terceira margem transcendental desse rio de águas caudalosas. Daí o esforço para permanecer próximo ao pai e, apesar do filho rejeitá-lo por ainda se sentir incapaz de estar à sua altura, ele tem a súbita consciência, mesmo sendo depois da morte, de que é possível se afastar da realidade da superfície e estabelecer-se no "profundo" do rio. Na realidade fluida da experiência de seu pai, neste ir e vir "rio abaixo, rio afora, rio a dentro" ou além das margens do rio. 


\title{
GUIMARÃES ROSA AND A RIVER BEYOND THE BANKS
}

\begin{abstract}
In Guimarães Rosa, more than linguistic or regionalist issues, human experience that becomes transcendent is highlighted. Through the understanding of existence, he obtains a third bank of the individual. The insertion of the third bank reflects a kind of uneasiness, for Guimarães Rosa suggests that we should abandon preconceived, and maybe secure, banks, and then establish another one. The present work analyses the short story "The Third Bank of the River", by marking the paths in which one looks for transcendence, a course that could break the boundaries between the metaphysical and the daily worlds. By establishing the third bank, a kind of necessary discontinuity takes place, which conducts the individual to perceive himself as authentic and, consequently, free.
\end{abstract}

Keywords: Philosophy. Memory. Truth.

\section{REFERÊNCIAS}

CANDIDO, Antonio. O homem dos avessos In: CANDIDO, Antonio. Tese e Antítese. 5. ed. Rio de Janeiro: Ouro sobre Azul, 2006.

ROSA, João Guimarães. A terceira margem do rio. In: ROSA, João Guimarães. Primeiras estórias. Rio de Janeiro: José Olympio, 1968.

Recebido em: 29/06/2015

Aceito em: 02/12/2015 